\title{
Percentage Change in Antenatal Body Mass Index as a Predictor of Neonatal Macrosomia
}

\author{
Chad A. Asplund, $M D^{1}$ \\ Dean A. Seebusen, MD, MPH \\ Terra L. Callaban, $M D^{1}$ \\ Cara Olsen, MS, MPH ${ }^{2}$ \\ 'Eisenhower Army Medical Center, Fort \\ Gordon, Georgia \\ ${ }^{2}$ Uniformed Services University of the \\ Health Sciences, Bethesda, Maryland
}

Conflicts of interest: none reported

\section{CORRESPONDING AUTHOR}

Chad Asplund, MD

Department of Family Medicine Eisenhower Army Medical Center Fort Gordon, GA 30905

chad.asplund@osumc.edu

\begin{abstract}
PURPOSE We wanted to evaluate the predictive value of percentage change in antenatal maternal body mass index (BMI) as it relates to macrosomia, as well as to compare change in pregnancy BMI with existing weight gain guidelines.
\end{abstract}

METHODS We analyzed data from 6 months of consecutive deliveries, focusing on first visit (first trimester) BMI, last visit (37 weeks or later) BMI, and fetal birth weight. Using regression and $\chi^{2}$ analyses, we evaluated the relationship between change in $\mathrm{BMI}$ and macrosomia.

RESULTS Of the 238 consecutive deliveries, we were able to analyze data from 186 , of which $15.6 \%(n=29)$ of the infants were macrosomic. Among macrosomic infants, $86.2 \%(25 / 29)$ of their mothers had a $25 \%$ or greater increase in BMI compared with 6.6\% (10/157) of mothers of normal-weight infants $(P<.001)$, for a relative risk $13.5 \%$ (95\% confidence interval $[\mathrm{Cl}], 7.3 \%-25.1 \%)$. Percentage change in BMI of $25 \%$ or greater had a sensitivity of $86.2 \%(95 \%$ $\mathrm{Cl}, 68.3 \%-96.1 \%)$, a specificity of $93.6 \%(95 \% \mathrm{Cl}, 88.6 \%-96.9 \%)$, a positive predictive value of $71.4 \%(95 \% \mathrm{Cl}, 53.7 \%-85.4 \%)$, and a negative predictive value $97.4 \%$ (95\% Cl, 93.4\%-99.3\%) for macrosomia. Logistic regression adjusted for maternal age, race, parity, and gravidity showed that those women whose BMI increased $25 \%$ or greater were more than 200 times more likely (odds ratio $[\mathrm{OR}]=219.3 ; 95 \% \mathrm{Cl}, 38.8-1,238.6 ; P<.001$ ) to give birth to a macrosomic infant. Further adjusting for initial BMI strengthened the association $(\mathrm{OR}=1,062.4 ; 95 \% \mathrm{Cl}, 83.2-13,572.2 ; P<001)$. Regardless of weight gain, when compared with Institute of Medicine weight gain recommendations, change in $\mathrm{BMI}$ or $25 \%$ or greater was associated with macrosomia $(P<.001)$.

CONCLUSION Independent of initial pregnancy BMI or absolute weight gain, an increase in maternal $\mathrm{BMI}$ of $25 \%$ or greater during pregnancy is highly predictive of macrosomia.

Ann Fam Med 2008:6;550-554. DOI: 10.1370/afm.903.

\section{INTRODUCTION}

$\mathrm{N}$ eonatal macrosomia affects between $3 \%$ and $15 \%$ of all pregnancies and is associated with shoulder dystocia, brachial plexus injury, skeletal injuries, meconium aspiration, perinatal asphyxia, hypoglycemia, and fetal death. ${ }^{1,2}$ Maternal complications of macrosomia include prolonged labor, labor augmentation with oxytocin, cesarean delivery, postpartum hemorrhage, infection, 3rd- and 4th-degree lacerations, thromboembolic events, and anesthetic accidents. ${ }^{2}$

Maternal obesity, multiparity, previous macrosomic infant, male fetus, maternal birth weight, maternal diabetes, prepregnancy body mass index (BMI), and excessive maternal weight gain are all risk factors for fetal macrosomia. ${ }^{1,3}$ Although maternal weight gain is frequently cited as a risk factor for macrosomia, ${ }^{3}$ current weight gain recommendations ${ }^{4}$ and consensus guidelines and are not evidence based. Additionally, there exist substantial variation in the literature and limited evidence supporting the strength of association between these risk factors and macrosomia. ${ }^{5}$ 
The purpose of this study was to evaluate the predictive value of percentage change in antepartum maternal BMI in predicting neonatal macrosomia, as well as to compare change in antepartum maternal BMI with existing weight gain guidelines.

\section{METHODS}

Based on personal experience and a small pilot study, we hypothesized that an increase in antenatal BMI by greater than $25 \%$ may be a predictor of macrosomia. The protocol was approved by the Eisenhower Army Medical Center (EAMC) institutional review board. We studied military beneficiaries whose babies were delivered by EAMC physicians from June 2006 to December 2006. The main eligibility criterion was the delivery of a live-born fetus at 37 to 42 weeks' gestation. Exclusion criteria included gestational diabetes, multiple gestation, entry to care after the first trimester, delivery before 37 weeks, or charts missing any of the data points.

Sample size for a power of 0.80 and an $\alpha$ of .05 was determined by using the lower end of the American College of Obstetrics and Gynecology (ACOG)-supported prevalence of fetal macrosomia of $10 \%$ plus a conservative value of relative risk supported in the literature of 2.5 (range, 2.0 $5.0),{ }^{1,2,6}$ which yielded a desired sample size of 151 deliveries (calculation was performed on statistical calculator at http:// stat.ubc.ca/ rollin/stats/ssize/caco.html.)

Demographic and pregnancy data were gathered from the electronic medical record. Infants were weighed on a Scale-Tronix scale (Scale-Tronix, Inc, White Plains, New York) within 1 hour of birth. BMI was calculated by the electronic medical record using the standard formula (weight $[\mathrm{kg}] /$ height $\left[\mathrm{m}^{2}\right]$ ) and recorded. Data were entered into an Excel spreadsheet (Microsoft Corp, Redmond, Washington) and reviewed by a coauthor for accuracy.

Contingency table analyses included $\chi^{2}$ analysis and Fisher's exact test to assess for significant association between percentage change in BMI and macrosomia. We used logistic regression analysis to compute the association between percentage change in BMI and fetal weight and compared percentage change in BMI with current weight gain guidelines. We used receiver operator character (ROC) curve analysis to assess the accuracy of this technique for predicting a fetal of weight greater than 4,000 g. SPSS 12.0 (SPSS Inc, Chicago, Illinois) was used for all data analyses.

\section{RESULTS}

A total of 238 EAMC deliveries occurred from June 2006 to December 2006. Fifty-two were excluded (30 were late entries to care, 13 mothers had gestational diabetes, 6 files had missing data, and 3 were multiple gestations). Among the 186 included in the final analysis, $56.5 \%$ of mothers were white and $25.8 \%$ were black. Average maternal age was 26.5 years; $32.8 \%$ were primigravidas. (Table 1 )

Of the 186 infants, $15.6 \%$ were macrosomic $(n=29)$. Of those macrosomic infants, $86.2 \%(25 / 29)$ of their mothers had a percentage change in antenatal BMI of $25 \%$ or greater compared with $6.6 \%(10 / 157)$ of the mothers of normal-weight infants $(P<.001)$, which yielded a relative risk 13.5 (95\% confidence interval [CI], 7.3\%-25.1\%). Percentage change in antenatal maternal BMI of $25 \%$ or greater had a sensitivity of $86.2 \%$ (95\% CI, $68.3 \%-96.1 \%)$, specificity of $93.6 \%$ (95\% CI, 88.6\%-96.9\%), a positive predictive value of $71.4 \%(95 \% \mathrm{CI}, 53.7 \%-85.4 \%)$, and a negative predic-
Table 1. Comparison of Antenatal Patients With and Without Macrosomic Infants

\begin{tabular}{|c|c|c|c|}
\hline Characteristic & $\begin{array}{c}\text { Normal Weight } \\
\quad(n=157)\end{array}$ & $\begin{array}{l}\text { Macrosomic } \\
(n=29)\end{array}$ & $P$ Value \\
\hline Age, mean y (SD) & $26.6(5.1)$ & $25.9(4.6)$ & .527 \\
\hline Age, $n(\%)$ & & & .378 \\
\hline$<25 y$ & $64(40.8)$ & $12(41.4)$ & \\
\hline $25-29 y$ & $55(35.0)$ & $11(37.9)$ & \\
\hline $30-34 y$ & $24(15.3)$ & $6(20.7)$ & \\
\hline$\geq 35$ y & $14(8.9)$ & $0(0)$ & \\
\hline Race, n (\%) & & & .274 \\
\hline White & $86(54.8)$ & $19(65.5)$ & \\
\hline Black & $44(28.0)$ & $4(13.8)$ & \\
\hline Other & $27(17.2)$ & $6(20.7)$ & \\
\hline Parity, n (\%) & & & .414 \\
\hline 0 & $68(43.3)$ & $11(37.9)$ & \\
\hline 1 & $51(32.5)$ & $13(44.8)$ & \\
\hline $2+$ & $38(24.2)$ & $5(17.2)$ & \\
\hline Gravidity, n (\%) & & & .928 \\
\hline 1 & $52(33.1)$ & $9(31.0)$ & \\
\hline 2 & $46(29.3)$ & $8(27.6)$ & \\
\hline $3+$ & $59(37.6)$ & $12(41.4)$ & \\
\hline \multicolumn{4}{|l|}{ BMI } \\
\hline Initial (SD) & $25.8(5.09)$ & $25.3(5.43)$ & .625 \\
\hline Final (SD) & $30.6(4.98)$ & $33.9(5.13)$ & .001 \\
\hline$\%$ change & $15.6(6.44)$ & $25.5(6.59)$ & $<.001$ \\
\hline Birth weight, g (SD) & $3,332(345)$ & $4,244(243)$ & $<.001$ \\
\hline
\end{tabular}


tive value of $97.4 \%$ (95\% CI, 93.4\%-99.3\%) for the prediction of neonatal macrosomia. Receiver operator characteristic (ROC) curve analysis showed an area under the curve of 0.89 (Figure 1).

Mother's age, race, parity, and gravidity were entered into a multivariate logistic regression model, along with an indicator for maternal BMI change of $25 \%$ or greater. After adjusting for other maternal characteristics, the odds of giving birth to a macrosomic infant were more than 200 times higher among mothers whose BMI increased at least $25 \%$, (odds ratio $[\mathrm{OR}]=219.3 ; 95 \%$ CI, 38.8-1,238.6; $P<.001)$. None of the other variables reached statistical significance at the 5\% level. Finally, after adjusting for initial BMI, the association was even stronger (adjusted $\mathrm{OR}=1,062.4 ; 95 \% \mathrm{CI}$, 83.2-13,572.2; $P<.001)$. Interactions between BMI change and other maternal characteristics were not statistically significant.

The data were further stratified by entry BMI and evaluated against the existing Institute of Medicine (IOM) weight gain guidelines. ${ }^{4}$ (Table 2) Gaining weight in excess of the IOM recommendations was a weaker predictor of macrosomia than percentage change in maternal BMI of $25 \%$ or greater. Furthermore, $11 \%$ of women whose weight gain was within or below the IOM guidelines also gave birth to macrosomic infants. Of these, $71 \%$ would have been predicted by a $25 \%$ or greater antenatal increase in BMI.

\section{DISCUSSION}

Although there is considerable variation in the definition of macrosomia in the literature, ${ }^{6} 4,000 \mathrm{~g}$ is the most widely used value and is the value at which maternal and neonatal complications increase. ${ }^{7}$ It is also the most common weight used when evaluating the predictive value of various methods to determine macrosomia antenatally. ${ }^{7}$ Because one goal was to compare our method with those already published, we also chose 4,000 $\mathrm{g}$ as our definition of macrosomia.

Several studies have found maternal estimate of birth weight offers a sensitivity of approximately
Figure 1. Receiver operator characteristic (ROC) curve of sensitivity of percentage change in body mass index (BMI) of $\geq 25 \%$ vs specificity.

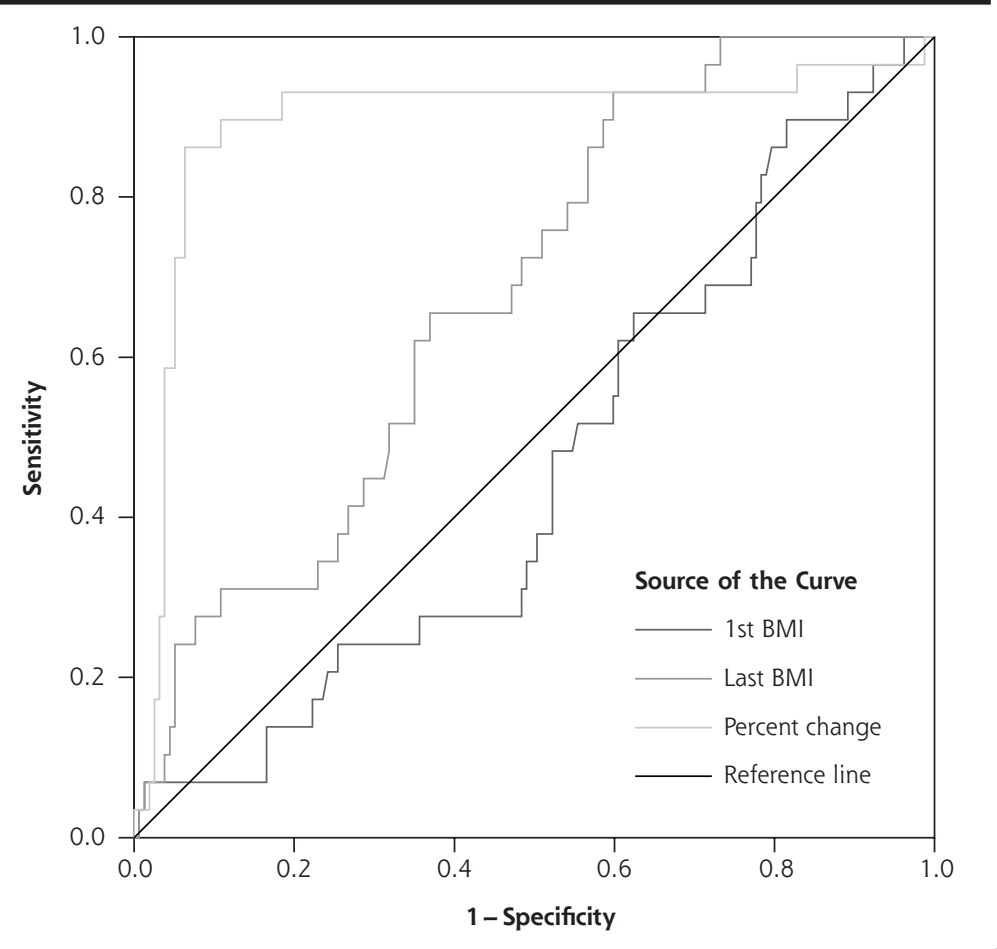

Table 2. Aggregate Data Comparing Macrosomia Within IOM Guidelines

\begin{tabular}{|c|c|c|c|}
\hline IOM Guidelines & $\begin{array}{c}\text { Macrosomic } \\
\mathbf{n}\end{array}$ & $\begin{array}{l}\text { Normal } \\
\text { Weight } \\
n\end{array}$ & $\begin{array}{c}\text { Total } \\
\mathbf{n}\end{array}$ \\
\hline \multicolumn{4}{|c|}{ Weight gain less than IOM recommendations ${ }^{\mathrm{a}}$} \\
\hline Change in $\mathrm{BMI} \geq 25 \%$ & 3 & 0 & 3 \\
\hline Change in $\mathrm{BMI}<25 \%$ & 1 & 48 & 49 \\
\hline Total & 4 & 48 & 52 \\
\hline \multicolumn{4}{|c|}{ Weight gain within IOM recommendations ${ }^{b}$} \\
\hline Change in $\mathrm{BMI} \geq 25 \%$ & 7 & 2 & 9 \\
\hline Change in $\mathrm{BMI}<25 \%$ & 3 & 64 & 67 \\
\hline Total & 10 & 66 & 76 \\
\hline \multicolumn{4}{|c|}{ Weight gain greater than IOM recommendationsc } \\
\hline Change in $\mathrm{BMI} \geq 25 \%$ & 15 & 7 & 22 \\
\hline Change in $\mathrm{BMI}<25 \%$ & 0 & 36 & 36 \\
\hline Total & 15 & 42 & 58 \\
\hline \multicolumn{4}{|c|}{$\mathrm{BMI}=$ body mass index; $\mathrm{IOM}=$ Institute of Medicine. } \\
\hline \multicolumn{4}{|l|}{$P<.001$} \\
\hline \multicolumn{4}{|c|}{$\begin{array}{l}\text { a Sensitivity }=75 \% \text {, specificity }=100 \% \text {, positive predictive value }=100 \% \text {, negative predictive value }=98 \% \text {. } \\
\text { b Sensitivity }=70 \% \text {, specificity }=97 \% \text {, positive predictive value }=78 \% \text {, negative predictive value }=96 \% \text {. } \\
\text { 'Sensitivity }=100 \% \text {, specificity }=84 \% \text {, positive predictive value }=68 \% \text {, negative predictive value }=100 \% \text {. }\end{array}$} \\
\hline
\end{tabular}


$56 \%{ }^{8,9}$ Clinical palpation is the traditional method used, but this method has a sensitivity similar to that of maternal estimate and is known to have a large predictive error, especially with large infants. ${ }^{10}$ Risk factor assessment has also been studied, but it has poor sensitivity and specificity. ${ }^{1}$ There have also been many studies of the use of sonography, with many different fetal measurement algorithms used, 4 of which specifically looked at prediction of neonatal macrosomia. ${ }^{11-15}$ These studies showed a sensitivity of $59 \%$, with area under the ROC curves from 0.75-0.85. Finally, several birthweight prediction algorithms have been used, with a sensitivity of $54 \%$ to $58 \%$ and a specificity of $84 \%$ to $92 \% .{ }^{11,16}$

Previous studies have suggested that obesity before pregnancy contributes to macrosomia, and when prepregnancy BMI increases, there is an increase in neonatal macrosomia and poor delivery outcomes. ${ }^{17-19}$ Although prepregnancy BMI and maternal weight gain correlate with fetal birth weight, our findings suggest that percentage change in maternal BMI may offer a better estimation of overall change in maternal body composition and fetal weight. Our report appears to be the first published study showing that antenatal increase in $\mathrm{BMI}$ of $25 \%$ or greater is a sensitive predictor of fetal macrosomia, regardless of initial BMI. Also, BMI is calculated by most electronic medical charting systems and is readily available to clinicians at point of care. Although the previous methods are accurate and have clinical utility, many of them require special equipment or formulas, and none is singularly predictive. Our lowtech method may be used as a sole predictor of neonatal macrosomia or to augment other methods, such as palpation, sonography, or prediction equations.

Guidelines for maternal weight gain have existed since the 1990 IOM report recommending weight gain for a specific prepregnancy BMI category (Table 3), which the ACOG adopted in 1993. ${ }^{4,20}$ Maternal weight gain recommendations, however, were based on observational studies in an attempt to balance the benefits of increased fetal growth with the risks of complicated labor and delivery, and the recommendations were not evidence-based. ${ }^{4}$ Using our method, the upper limit of weight gain may be individualized for obstetric patients. For example, for a 5 foot 1 inch tall woman who started pregnancy at a weight of 110 pounds $(\mathrm{BMI}=20.8)$, an increase in BMI of $25 \%$ $(\mathrm{BMI}=26.0)$ would be caused by a weight gain of 27 pounds; therefore, 27 pounds could be used as the upper limit of weight gain, compared with the 35 to 40 pounds recommended by the IOM guidelines.

The limitations of our study include our unique patient population and their access to medical care. Our military population has good access to care at
Table 3. Institute of Medicine (IOM) Guidelines for Weight Gain in Pregnancy

\begin{tabular}{lc}
\hline Initial Body Mass Index & $\begin{array}{c}\text { IOM Recommended } \\
\text { Weight Gain, Ib }\end{array}$ \\
\hline$<19.8$ (underweight) & $28-40$ \\
$19.8-26.0$ (normal) & $25-35$ \\
$26.1-29.0$ (overweight) & $15-25$ \\
$>29.0$ (obese) & At least 15 \\
\hline From the Institute of Medicine. ${ }^{4}$ & \\
\hline
\end{tabular}

no cost, may be more physically fit than the civilian sector, and may possess lower prepregnancy weight and weight gain during pregnancy. Also, in an effort to minimize confounders, we excluded women with gestational diabetes. This exclusion may be viewed as a limitation, because detecting macrosomia in diabetic patients may actually help to direct management decisions.

In conclusion, fetal macrosomia has been consistently associated with neonatal and maternal complications. Any indicator that helps diagnose macrosomia may allow clinicians to make better choices regarding timing and mode of delivery, as well as prepare for emergencies. Our findings support that regardless of initial pregnancy BMI or total amount of maternal weight gain, an antepartum maternal BMI increase of $25 \%$ or greater is predictive of neonatal weight greater than 4,000 g. This method is easy to use without any special equipment or expert clinical skills, and it has shown a better sensitivity and specificity than previously described methods. Finally, our method may allow clinicians to individualize maternal weight gain recommendations, replacing previous IOM guidelines.

Antenatal percentage change in BMI was highly predictive of macrosomia in our unique patient population. Future studies in a larger, more heterogeneous population are needed. Prospective studies will be desirable to test antenatal change in BMI as a means for influencing maternal weight gain and detecting and managing delivery of macrosomic fetuses.

To read or post commentaries in response to this article, see it online at http://www.annfammed.org/cgi/content/full/6/6/550.

Key words: Fetal macrosomia; body mass index; pregnancy

Submitted November 5, 2007; submitted, revised, June 5, 2008; accepted June 10, 2008.

Phase 1 of this study was presented at the North American Primary Care Research Group (NAPCRG) Annual Meeting, Vancouver, British Columbia, October 22, 2007. The complete study was presented at the Uniformed Services Academy of Family Physicians Annual Meeting, Portland, Oregon, March 152008. 


\section{References}

1. Golditch IM, Kirkman K. The large fetus. Management and outcome. Obstet Gynecol. 1978;52(1):26-30.

2. Boulet SL, Alexander GR, Salihu HM, et al. Macrosomic births in the United States: determinants, outcomes, and proposed grades of risk. Am J Obstet Gynecol. 2003;188(5):1372-1378.

3. Spellacy WN, Miller S, Winegar A, et al. Macrosomia-maternal characteristics and infant complications. Obstet Gynecol. 1985;66(2):158-161.

4. Institute of Medicine (United States) Subcommittee on Nutritional Status and Weight Gain During Pregnancy. Nutrition During Pregnancy. Washington, DC: National Academy Press; 1990.

5. Sacks DA, Chen W. Estimating fetal weight in the management of macrosomia. Obstet Gynecol Surv. 2000;55(4):229-239.

6. Nahum GG. Detecting and managing fetal macrosomia. Contemp Ob Gyn. 2000;6:89-119.

7. American College of Obstetricians and Gynecologists (ACOG). Fetal macrosomia. Washington, DC: American College of Obstetricians and Gynecologists (ACOG); 2000. ACOG practice bulletin; no. 22.

8. Herrero RL, Fitzsimmons J. Estimated fetal weight. Maternal vs. physician estimate. J Reprod Med. 1999;44(8):674-678.

9. Chauhan SP, Cowan BD, Magann EF, et al. Intrapartum detection of a macrosomic fetus: clinical versus 8 sonographic models. Aust N Z J Obstet Gynaecol. 1995;35(3):266-270.

10. Ong HC, Sen DK. Clinical estimation of fetal weight. Am J Obstet Gynecol. 1972;112(7):877-880.

11. Wikstrom I, Bergstrom R, Bakketeig L, et al. Prediction of high birthweight from maternal characteristics, symphysis fundal height and ultrasound biometry. Gynecol Obstet Invest. 1993;35(1):27-33.
12. Chauhan SP, West DJ, Scardo JA, et al. Antepartum detection of macrosomic fetus: clinical versus sonographic, including soft-tissue measurements. Obstet Gynecol. 2000;95(5):639-642.

13. Pollack RN, Hauer-Pollack G, Divon MY. Macrosomia in postdates pregnancies: the accuracy of routine ultrasonographic screening. Am J Obstet Gynecol. 1992;167(1):7-11.

14. O'Reilly-Green CP, Divon MY. Receiver operator characteristic curves of sonographic estimated fetal weight for prediction of macrosomia in prolonged pregnancies. Ultrasound Obstet Gynecol. 1997;9(6):403-408.

15. Chauhan SP, Grobman WA, Gherman RA, et al. Suspicion and treatment of macrosomic fetus: a review. Am J Obstet Gynecol. 2005;193(2):332-346.

16. Nahum GG, Stanislaw H, Huffaker BJ. Accurate prediction of term birth weight from prospectively measurable maternal characteristics. J Reprod Med. 1999;44(8):705-712.

17. Cnattingius S, Bergstrom R, Lipworth L, et al. Prepregnancy weight and the risk of adverse pregnancy outcomes. $N$ Engl J Med. 1998;338(3):147-152.

18. Wolfe $\mathrm{H}$. High prepregnancy body-mass index-a maternal-fetal risk factor. N Engl J Med. 1998;338(3):191-192.

19. Jensen DM, Damm P, Sorensen B, et al. Pregnancy outcome and prepregnancy body mass index in 2549 glucose-tolerant Danish women. Am J Obstet Gynecol. 2003;189(1):239-244.

20. American College of Obstetricians and Gynecologists. Nutrition During Pregnancy. Washington, DC: American College of Obstetricians and Gynecologists, 1993; Technical Bulletin no 179. 